\title{
Article \\ Silver/Polypyrrole-Functionalized Polyurethane Foam Embedded Phase Change Materials for Thermal Energy Harvesting
}

\author{
Dongli Fan ${ }^{1,2}$, Yuan Meng ${ }^{2}$, Yuzhuo Jiang ${ }^{2}$, Siyi Qian ${ }^{2}$, Jie Liu ${ }^{2}$, Yuzhi Xu ${ }^{3}$, Dangsheng Xiong ${ }^{1, *}$ and \\ Yufeng Cao ${ }^{2, * \mathbb{D}}$ \\ 1 School of Materials Science \& Engineering, Nanjing University of Science and Technology, \\ Nanjing 210094, China; fdlsky@ntu.edu.cn \\ 2 School of Chemistry and Chemical Engineering, Nantong University, Nantong 226019, China; \\ meng971123@163.com (Y.M.); yuzhuojiang@163.com (Y.J.); 18751310311@163.com (S.Q.); \\ jliu93@ntu.edu.cn (J.L.) \\ 3 Institute of Chemical Industry of Forest Products, Chinese Academy of Forestry, Nanjing 210042, China; \\ xuyuzz@163.com \\ * Correspondence: xiongds@163.com (D.X.); yufengntu@ntu.edu.cn (Y.C.)
}

Citation: Fan, D.; Meng, Y.; Jiang, Y.; Qian, S.; Liu, J.; Xu, Y.; Xiong, D.; Cao, Y. Silver/Polypyrrole-Functionalized Polyurethane Foam Embedded Phase Change Materials for Thermal Energy Harvesting. Nanomaterials 2021, 11, 3011. https://doi.org/10.3390/ nano11113011

Academic Editor: Jürgen Eckert

Received: 29 September 2021

Accepted: 5 November 2021

Published: 9 November 2021

Publisher's Note: MDPI stays neutral with regard to jurisdictional claims in published maps and institutional affiliations.

Copyright: (c) 2021 by the authors. Licensee MDPI, Basel, Switzerland. This article is an open access article distributed under the terms and conditions of the Creative Commons Attribution (CC BY) license (https:// creativecommons.org/licenses/by/ $4.0 /)$.

\begin{abstract}
Conversion of solar energy into thermal energy stored in phase change materials (PCMs) can effectively relieve the energy dilemma and improve energy utilization efficiency. However, facile fabrication of form-stable PCMs (FSPCMs) to achieve simultaneously energetic solar-thermal, conversion and storage remains a formidable challenge. Herein, we report a desirable solar-thermal energy conversion and storage system that utilizes paraffin (PW) as energy-storage units, the silver/polypyrrole-functionalized polyurethane (PU) foam as the cage and energy conversion platform to restrain the fluidity of the melting paraffin and achieve high solar-thermal energy conversion efficiency (93.7\%) simultaneously. The obtained FSPCMs possess high thermal energy storage density $(187.4 \mathrm{~J} / \mathrm{g})$ and an excellent leak-proof property. In addition, 200 accelerated solar-thermal energy conversion-cycling tests demonstrated that the resultant FSPCMs had excellent cycling durability and reversible solar-thermal energy conversion ability, which offered a potential possibility in the field of solar energy utilization technology.
\end{abstract}

Keywords: phase change materials; silver/polypyrrole-functionalized polyurethane foam; solar-thermal energy conversion

\section{Introduction}

The growing public concerns about energy shortage and environmental degradation caused by the over-consumption of non-renewable energy resources have encouraged people to explore and develop available renewable energy and energy conversion techniques for the sustainable development of human civilization [1-3]. Solar energy is a promising renewable energy for human beings and the earth's surface receives a large quantity of solar irradiation every day. The conversion of solar energy into heat is an appealing way to alleviate the energy crisis and environmental concerns and improve solar energy utilization efficiency [4-7]. However, solar energy is a representative time-dependent energy resource with an intermittent and discontinuous attribute, which has undermined its widespread exploitation and commercial applications. Latent heat storage technologies based on organic PCMs can gather thermal energy from solar irradiation, which can conquer the intermittency and instability of solar energy [8-10]. In this process, solar energy is captured and converted into thermal energy stored within the organic PCMs via solid-liquid phase change. When solar irradiation is not available, the stored latent heat can be released to regulate the local temperature fluctuation. 
Over the past few decades, organic PCMs have been extensively used in various high technology fields, including solar energy conversion and storage [11-13], smart thermosregulated textiles [14-16], thermal protection electronic devices $[17,18]$ and healthcare services [19-21] due to its high latent heat storage capacity, desired physicochemical stability and remarkable energy-saving capability [22,23]. Nevertheless, the possibility of liquid leakage and inferior solar-thermal energy conversion efficiency has severely restricted the practical applications for most commonly available organic PCMs. One scalable method is to design and develop form-stable PCMs (FSPCMs) with improved solar-thermal energy conversion ability, which can not only remove the leakage threats but also gather thermal energy from solar irradiation [24-26]. Polyaniline (PANI) [27,28], polydopamine (PDA) [29-31] and polypyrrole (PPy) [32,33] as kinds of polymer-based light absorber materials have been introduced into organic PCMs due to their impressive solar-thermal conversion property. Nevertheless, stable solar-thermal energy harvesting and high latent heat energy storage density with ignorable heat waste for the FSPCMs remains one of the hotspots due to liquid leakage, low heat-conducting property and limited energy conversion efficiency, obstructing their further development and business application.

Herein, we constructed a series of novel FSPCMs with impressive solar-thermal energy conversion ability, where the silver/polypyrrole composites coating polyurethane (PU) foam was used as the building scaffolds and energy conversion platform and paraffin as thermal energy storage mediums (see Figure S1). The 3D continuous porous structures allowed the PU foam to be viewed as the building scaffolds to capture and constrain the melting paraffin, promising the FSPCMs an outstanding anti-leakage property. The coated silver/polypyrrole composites on PU skeletons essentially provided an impressive solarthermal energy conversion ability and heat-conducting property, thus collecting solar irradiation and converting it into thermal energy, which was delivered along with the skeletons of the PU foam and stored in PCMs. The preparation, characterization and application of the developed FSPCMs were systematically investigated with the aim of obtaining positively improved FSPCMs for potential applications, satisfying the needs of different solar-thermal energy conversion and storage systems.

\section{Experimental Section}

\subsection{Materials}

Pyrrole (99\%), $\mathrm{Fe}\left(\mathrm{NO}_{3}\right)_{3}(\geq 98.5 \%)$ and ammonium persulfate (APS, $\geq 98.5 \%$ ) were obtained from Nantong Feiyu Biochemical Co., Ltd., Nantong, China. $\mathrm{AgNO}_{3}(\geq 99.8 \%)$ and paraffin (PW, $T_{\mathrm{m}} \approx 56-58{ }^{\circ} \mathrm{C}$ ) was provided by Sino Pharm Chemical Reagent Co., Ltd., Beijing, China. Deionized water was obtained from Chinese Local Supermarkets. Polyurethane (PU) foam was prepared according to a previous literature procedure with some modifications [34]. All chemicals were utilized as received without further purification.

\subsection{Preparation of PPy@PU}

The PPy@PU was fabricated according to a previous literature procedure with a minor modification [35]. Generally, a piece of PU foam with a thickness of $15 \mathrm{~mm}$ was immersed into $0.1 \mathrm{M}$ pyrrole aqueous solution at room temperature for $24 \mathrm{~h}$ to guarantee penetration equilibrium of pyrrole into the PU 3D network structures. Subsequently, the abovementioned PU with pyrrole infiltrative was immediately immersed into $0.1 \mathrm{M}$ APS aqueous solution for $1 \mathrm{~h}$, where the color of the PU changed from light yellow to black. Finally, the as-fabricated PPy@PU was repeatedly washed with deionized water, followed by freeze-drying. The prepared PPy@PU was denoted as UP.

\subsection{Preparation of $A g / P P y @ P U$}

A block of PU foam with a thickness of $15 \mathrm{~mm}$ was immersed into $0.002 \mathrm{M}$ pyrrole aqueous solution at environment temperature for $24 \mathrm{~h}$ to guarantee penetration equilibrium of pyrrole into the PU 3D porous structures. Subsequently, the abovementioned PU with 
pyrrole infiltrative was immediately immersed into an oxidant aqueous solution for 1 week to complete the polymerization, where the color of the solution changed from light yellow to black. Finally, the as-prepared Ag/PPy@PU was thoroughly washed with deionized water, followed by freeze-drying. The aqueous solution of $\mathrm{AgNO}_{3}$ and $\mathrm{Fe}\left(\mathrm{NO}_{3}\right)_{3}$ was employed as the oxidant, and the mole ratio of oxidants/pyrrole was 2.5. The concentration of the oxidants used in the polymerization is shown in Table S1. The fabricated Ag/PPy@PU was denoted as UPA $x\left(x=1,2,3\right.$ and 4, which represents the concentration of $\mathrm{AgNO}_{3}$ in oxidants aqueous solution).

\subsection{Preparation of the FSPCMs}

The as-prepared UPA $x$ were immersed into the melted paraffin to guarantee penetration equilibrium of the melted paraffin into the 3D porous structures of UPA $x$ via vacuum-assisted conditions and was maintained at $80^{\circ} \mathrm{C}$ for $6 \mathrm{~h}$; afterwards, the FSPCMs were obtained and referred to as UPA $x / \mathrm{PW}$. The fabrication process for the UP/PW was the same.

\subsection{Characterizations}

The prepared samples' morphologies were observed using SEM observation (ZEISS Gemini SEM 300, Baden-Württemberg, Germany). FT-IR spectra (Nicolet Nexus 6700, Madison, WI, USA) and XRD analysis (Bruker D8 advance, Karlsruhe, Germany) were conducted to investigate the structure and crystalline property of the prepared samples in this work, respectively. The melting and crystallization enthalpies of samples were measured via a DSC analysis (DSC 2500, TA Instruments, New Castle, PA, USA). The thermal conductivity of samples was confirmed by a transient plane heat source (hot disk) method (DRE-III, Xiangtan Xiangyi Instrument Co., Ltd., Xiangtan, China). On the other hand, a solar simulator (CEL-PF300-T10, Beijing China Education Au-light Co., Ltd., Beijing, China) and an infrared camera (FLIR E5-XT, North Billerica, MA, USA) were employed to observe the solar-thermal energy conversion, storage and release behavior of the prepared samples. Meanwhile, the solar-thermal energy harvesting and storage of sample during 200 times cycling tests was confirmed by simulative light source and DSC analysis, and the structural stability was also verified through FT-IR and XRD analysis, respectively.

\section{Results and Discussion}

\subsection{Morphology and Structure of the FSPCMs}

SEM images, as shown in Figure $1 \mathrm{a}-\mathrm{c}$, were utilized to monitor the morphologies evolution of PU, UP, UPA $x$ and UPAx/PW. The as-prepared PU foam showed a 3D continuous porous structure, and the walls of pores are relatively smooth (Figure 1a). The UP skeletons were also observed as presented in Figure 1b, and the walls of UP skeletons exhibited a coarse landscape texture due to the pyrrole in situ polymerization on the surface of PU skeletons. Taking UPA3 as an example, after further modifying the PU with Ag/PPy composites, the walls of its skeletons became rougher (Figure 1c), which was more conducive to arresting and constraining the melting PW due to capillary effect and intermolecular interaction. To further confirm the distribution of Ag/PPy composites within the PU skeletons, the elemental mapping measurement was conducted, and the corresponding results are presented in Figure $1 \mathrm{e}-\mathrm{i}$. As we can see, the elemental C, $\mathrm{O}, \mathrm{N}$ and Ag mainly assembled on the walls of PU skeletons homogeneously. Moreover, thanks to the local surface plasma resonance effect (LSPR) of silver [36], the UPA3 had enhanced solar harvesting ability and heat conductivity, resulting in the rapid temperature increase of $98.7^{\circ} \mathrm{C}$ of the UPA3 in $1.0 \mathrm{~min}$ under $300 \mathrm{~mW} / \mathrm{cm}^{2}$ irradiation power (Figure S2a); in contrast, the pure PU foam only reached $49.7^{\circ} \mathrm{C}$ (Figure S2b). The UPA $x$ were immersed into the melting paraffin to prepare a group of novel FSPCMs under the vacuum-assisted condition. The morphology of the representative UPA3/PW was investigated through SEM observation. Figure 1d showed that the absorbed PW fully filled in the inner cavities or tightly intertwined with the skeletons of the UPA3, indicating the UPA $x$ offered a 3D 
continuous porous platform to effectively arrest and constrain the melting PW molecules. On the other hand, as shown in Figure S3, even if the working temperature was above PW's phase-transition temperature, the FSPCMs not only maintained a solid state but also were leak-proof.
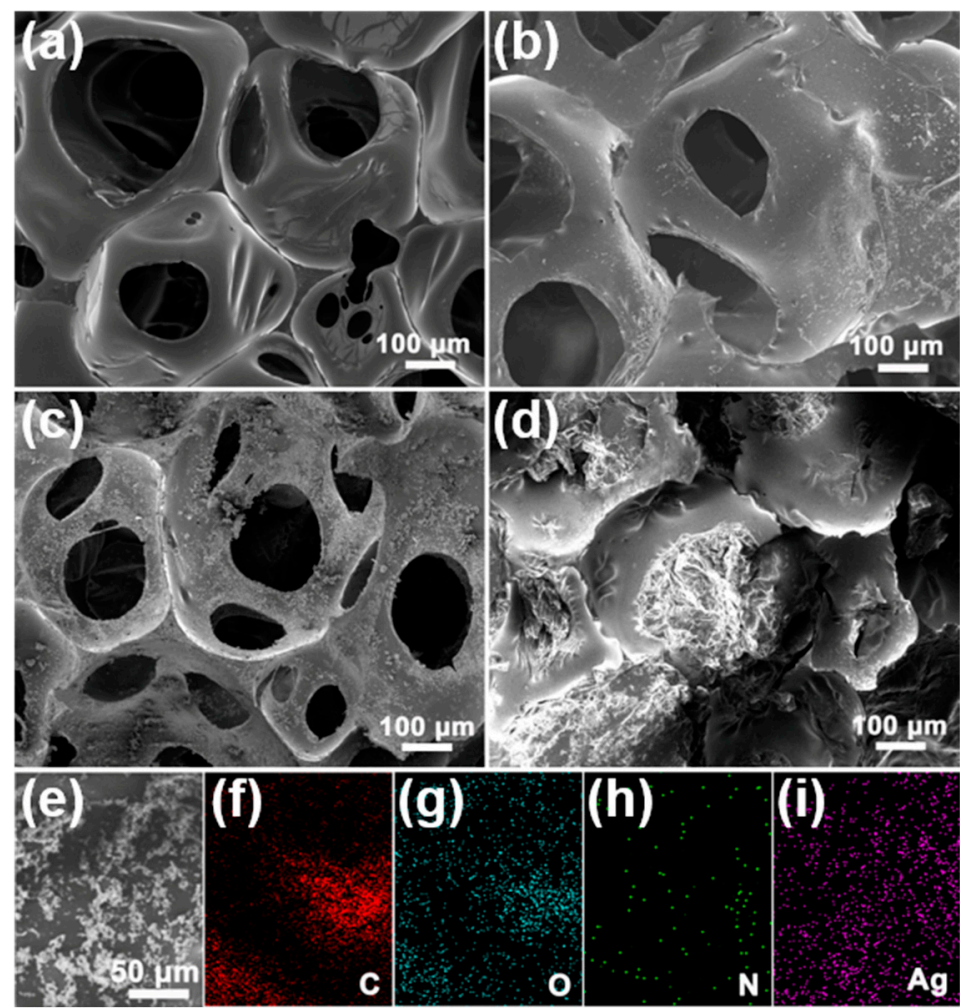

Figure 1. SEM images of (a) PU, (b) UP, (c) UPA3, (d) UPA3/PW and (e-i) elemental mapping images of UPA3.

The structural feature and crystallization property of the developed FSPCMs were investigated by FT-IR spectra and XRD diffraction, and the results are depicted in Figure 2 and Figure S4. As we can see, no new characteristic absorption bands and diffraction peaks were evidently observed, demonstrating only that physical interaction existed between the components of the FSPCMs, and the crystalline property of PW was also not be destroyed by the volume restriction effect of the UPAx.
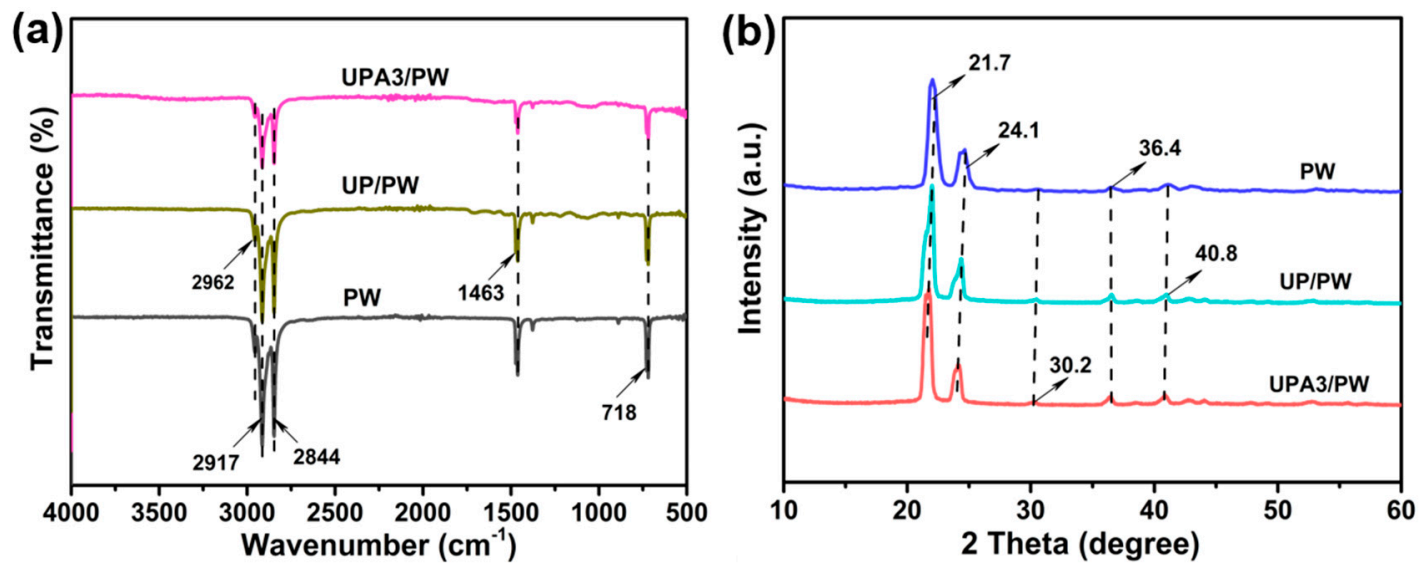

Figure 2. (a) FT-IR spectra and (b) XRD patterns of PW, UP/PW and UPA3/PW. 


\subsection{Thermal Properties of the FSPCMs}

Latent heat storage density is a critical parameter in determining the development prospect of FSPCMs in practical applications. DSC analysis was used to measure the melting and crystallization enthalpies of the prepared FSPCMs in this work, and the experimental results are presented in Figure 3a,b. As depicted in Figure $3 a, b$, a melting endothermic peak and a crystallization exothermic peak appeared at $54.6^{\circ} \mathrm{C}$ and $52.2^{\circ} \mathrm{C}$ on the DSC heating and cooling curves of pristine PW, corresponding to the thermal energy charging and discharging process, respectively. The melting temperatures of UP/PW, UPA1/PW, UPA2/PW, UPA3/PW and UPA4/PW changed by $0.9,1.8,1.5,1.9$ and $1.5^{\circ} \mathrm{C}$, and the freezing temperatures changed by $0.5,-1.0,-0.4,-1.0$, and $0.1{ }^{\circ} \mathrm{C}$, respectively, which was slightly different than that of pure PW. In part, this is because the steric effect of the PU foam imposed restrictions on the molecular movement and spatial arrangement of $\mathrm{PW}$ and postponed the phase transformation behavior [37]. It can be seen from Table S2 that the obtained FSPCMs offered a relatively high latent heat storage density, and the melting and crystal enthalpies ranged from 185.2 to $197.9 \mathrm{~J} / \mathrm{g}$ and 182.0 to $196.7 \mathrm{~J} / \mathrm{g}$, respectively. The available latent heat storage capacity of the FSPCMs was less than that of pristine PW, because the PU foam in the FSPCMs cannot offer up the melting and crystal enthalpies. In addition, the melting and crystallization properties of PW in the FSPCMs were blocked at some level by the PU foam, which also led to the partial decline of the melting and crystal enthalpies. Nevertheless, as shown in Table S3, the latent heat storage density of the developed FSPCMs in this work reached 87.1 to $93.2 \%$ of pristine PW, which was higher or comparable to the recently reported data $[27,28,38-43]$.
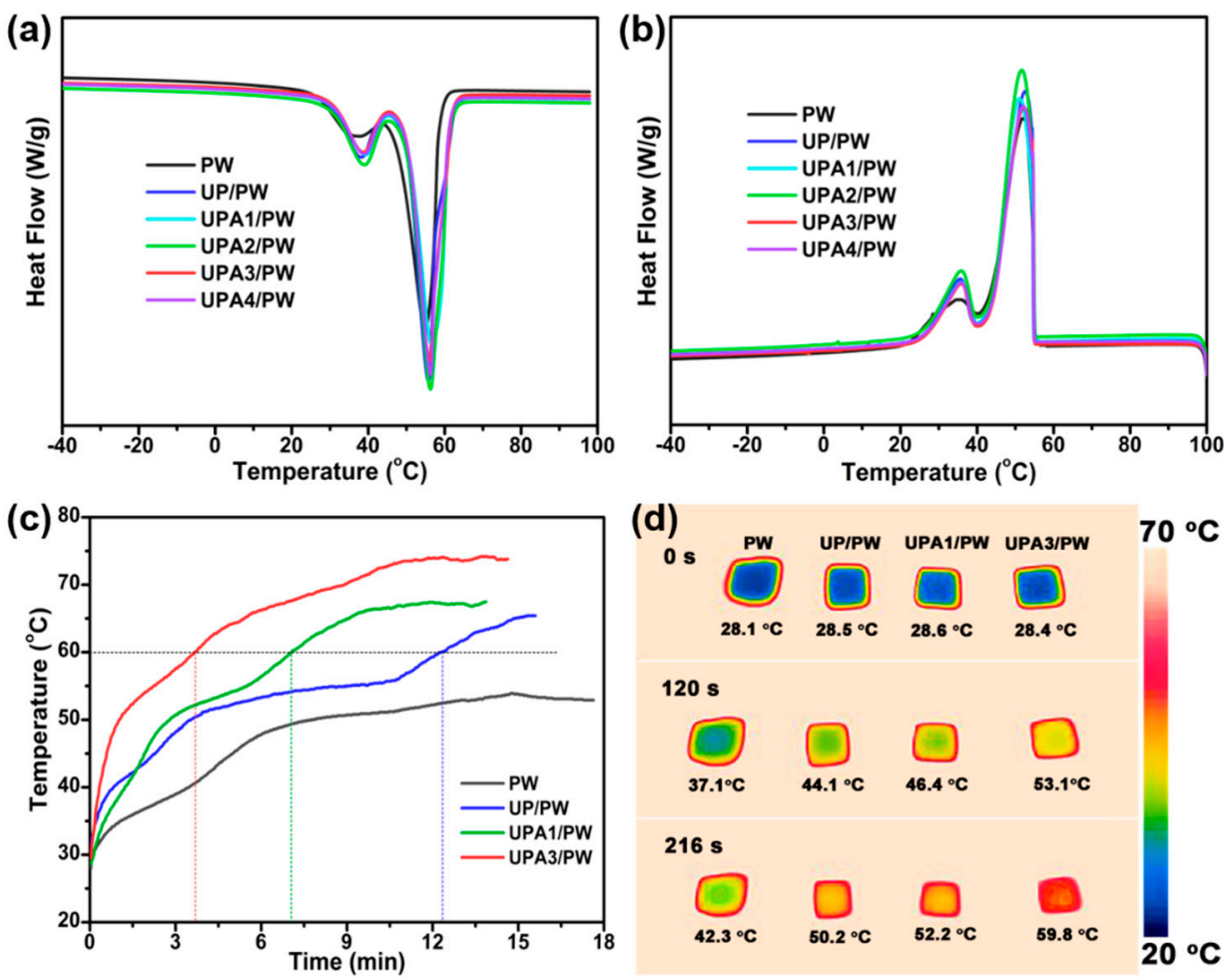

Figure 3. Thermal properties of PCCs. The DSC (a) heating and (b) cooling curves of PW and PCCs; (c) Temperature-time curves and (d) Infrared thermal images of PW, UP/PW, UPA1/PW and UPA3/PW during the charging process.

In addition, it can be seen from Figure S5 that the pure PW showed a low thermal conductivity of $0.271 \mathrm{~W} \mathrm{~m}^{-1} \mathrm{~K}^{-1}$, whereas the thermal conductivities of PU/PW UP/PW and UPA3/PW sequentially increased. The maximum thermal conductivity is up to $0.391 \mathrm{~W} \mathrm{~m}^{-1} \mathrm{~K}^{-1}$ for the UPA3/PW, which is $144 \%$ higher than that of the pure PW, which 
could contribute to the fast charging and discharging. The heat transfer rate of samples during the charging process was also investigated and shown in Figure $3 c$,d. As presented in Figure $3 c$, to achieve a temperature of $60^{\circ} \mathrm{C}$ from an ambient temperature, the heating times of UP/PW, UPA1/PW and UPA3/PW were 12.3, 7.0 and $3.7 \mathrm{~min}$, respectively. It was difficult to reach $60{ }^{\circ} \mathrm{C}$ for pure paraffin due to its inferior heat-conducting property. Furthermore, as shown in Figure 3d, the heating rate of the UPA3/PW was evidently faster than other samples under the same interval time. The above results suggest that the heat transfer rate of these FSPCMs increased with the increasing doping amount of Ag/PPy composites, which makes them a promising opportunity for rapid thermal energy storage.

\subsection{Solar-Thermal Energy Harvesting and Storage}

High energy conversion efficiency and fast thermal transmission are essential to the FSPCMs. PPy as an efficient solar-thermal agent has been successfully used to improve the solar absorption capability of the organic PCMs [32,33], but its thermal conductivity was relatively poor. Silver nanoparticles could enhance the heat-conducting property and improve the visible light absorption for the organic PCMs simultaneously [36]. Therefore, in these developed FSPCMs, the assembled Ag/PPy composites promised satisfactory solar-thermal energy conversion ability and the PU foam coating with Ag/PPy composites contributed to the avenues for rapid energy transfer so that the absorbed thermal energy could be charged into the PW. Figure 4a shows that the empty UPA3 was irradiated under $50 \sim 300 \mathrm{~mW} / \mathrm{cm}^{2}$ light power. The temperature of the UPA3 rapidly rose with the increase in light power and ultimately reached an equilibrium temperature $\left(T_{\mathrm{e}}\right)$, where the absorbed heat from solar irradiation balanced the heat loss from the UPA3 with the surroundings. When the solar irradiation was not available, the temperature of the sample fell to room temperature in short order, showing the rapid thermal runaway. Therefore, the result indicates that the UPA3 offers desirable light-thermal energy conversion ability and excellent thermal transmission performance. For the obtained FSPCMs, the introduced PPy and Ag/PPy composites can effectively capture and convert light into thermal energy stored by PW through the phase-transition process. As shown in Figure $4 \mathrm{~b}$, the heating rate of the UPA3/PW was evidently faster than PU/PW and UP/PW at the same irradiation time, indicating that the Ag/PPy composites offer higher solar harvesting and conversion efficiency than pure PPy. On the other hand, we can see from Figure 4c that the temperature-time evolution curves of the UPA3/PW under different light power revealed obvious endothermic and exothermic platforms, corresponding to the heat energy storage and release, respectively. The solar-thermal energy conversion efficiency $(\eta)$ of the composite FSPCMs was calculated according to the Equation [6]:

$$
\eta=\frac{m \times \Delta H_{\mathrm{m}}}{I A \times\left(t_{f}-t_{0}\right)} \times 100 \%
$$

where $m$ is the mass of the composite FSPCMs, $\Delta H_{\mathrm{m}}$ is the melting enthalpy of the composite FSPCMs, $I$ is the irradiation intensity, $A$ is the surface area of the sample and $t_{f}$ and $t_{0}$ are the termination and onset time of phase transformation, respectively. Therefore, the calculated $\eta$ value of the UPA3/PW reached $93.7 \%$ at $300 \mathrm{~mW} / \mathrm{cm}^{2}$ power intensity, which is higher than some other reported data $(60 \% \sim 86 \%)$ [32,44-47]. In addition, an infrared camera recorded the temperature changes of the UPA3/PW under $300 \mathrm{~mW} / \mathrm{cm}^{2}$ light power. It can be seen from Figure $4 \mathrm{~d}$ that the temperature rapidly increased from 25.7 to $48.7^{\circ} \mathrm{C}$ in $0.7 \mathrm{~min}$ as the UPA3/PW absorbed heat energy directly from solar. Subsequently, the temperature was maintained between 48.7 and $56.3^{\circ} \mathrm{C}$ for about $1 \mathrm{~min}$, reaching the melting platform (Figure $3 \mathrm{c}$ ), where the harvested heat was directly stored into the PW through the phase-transformation process. As irradiation time passed by, the temperature ultimately reached a saturation temperature $\left(64.5^{\circ} \mathrm{C}\right)$ in $2.1 \mathrm{~min}$. On the other hand, once the light irradiation was not available, the temperature of the specimen declined quickly until it reached an obvious freezing platform between 54.9 and $48.5^{\circ} \mathrm{C}$, demonstrating that 
latent heat stored within PW can be discharged via natural cooling. This exothermic process was maintained for about $2.0 \mathrm{~min}$, which contributed to the temperature regulation for smart fabrics, electron devices and so on. The results prove that the developed UPA3/PW could collect available thermal energy from solar irradiation and offers potential use in the field of solar energy utilization technique.
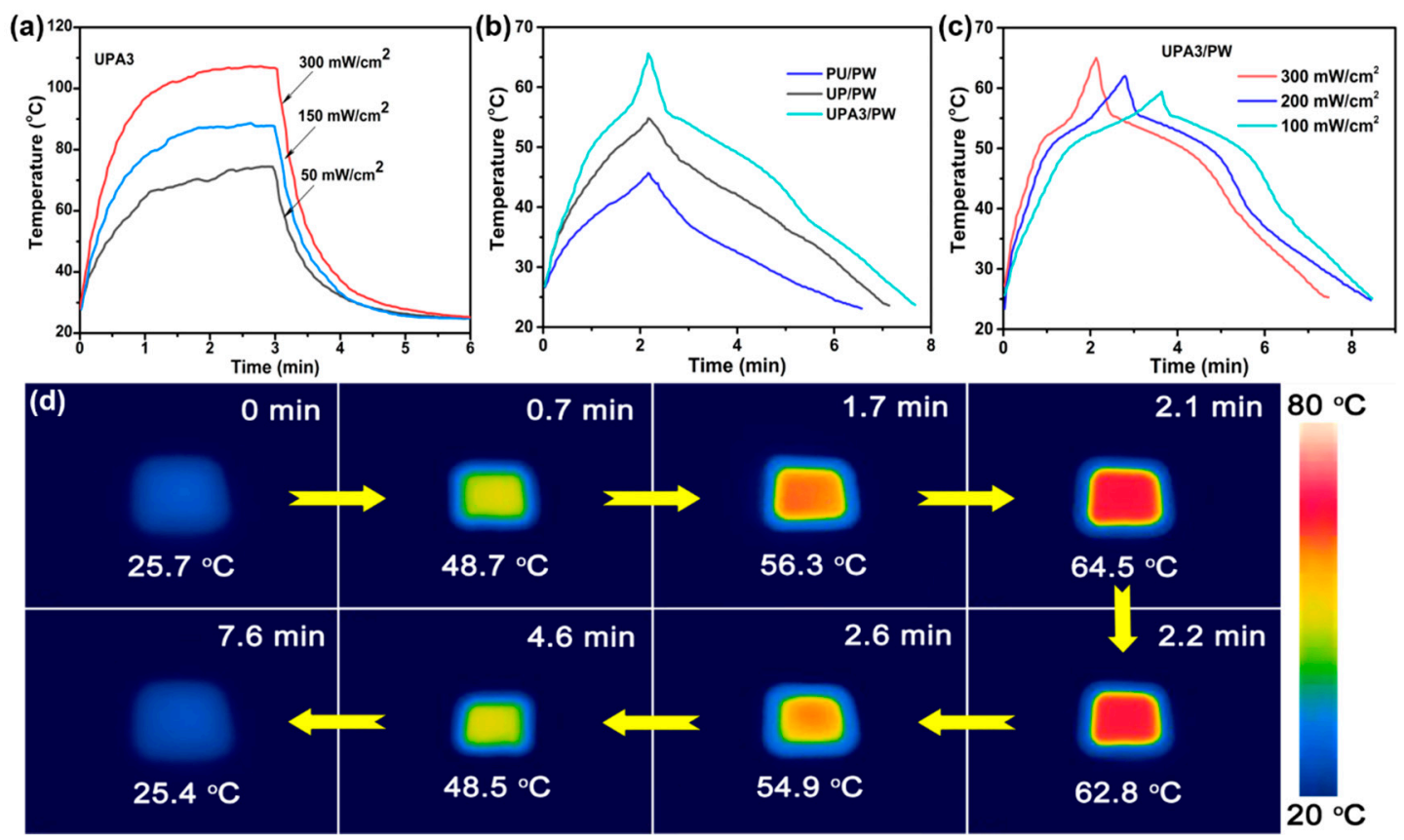

Figure 4. Time-temperature curves of (a) UPA3, (b) PU/PW, UP/PW and UPA3/PW, and (c) UPA3/PW $(13 \times 13 \times 3.0 \mathrm{~mm}$, mass: $142.9 \mathrm{mg}$ ) under various solar intensity; (d) Infrared thermal images showing the solar-thermal energy conversion, storage and release behavior of the UPA3/PW.

\subsection{Cycling Durability of the FSPCMs}

The results of the accelerated energy conversion cycling tests evaluating the cycling durability of the UPA3/PW are shown in Figure 5 . When the illumination intensity was $300 \mathrm{~mW} / \mathrm{cm}^{2}$ light power, the UPA3 $/ \mathrm{PW}$ reached a saturation temperature $\left(T_{\mathrm{s}}=64.5^{\circ} \mathrm{C}\right)$ within $2.1 \mathrm{~min}$, which declined as the solar simulator was evacuated (Figure 4c). In addition, we can see from Figure $5 \mathrm{a}, \mathrm{b}$ that the time-temperature changing curves of the UPA3/PW during the 200 accelerated solar-thermal energy conversion cycling tests remained virtually unchanged. The heat storage properties of the UPA3/PW show almost no fluctuation before and after the accelerated cycling tests (Figure $5 \mathrm{c}$ and Table S2). Moreover, as shown in Figure 5d,e, the FT-IR spectra and XRD patterns of the UPA3/PW did not detect new absorption peaks before and after 200 accelerated solar-thermal energy conversion cycling tests either, showing that the accelerated cycling tests had not exerted a negative impact on its structure and crystallizing behavior. The above results show that the UPA3/PW offered excellent cycling durability, unlocking a potential possibility to use it in commercial applications. 

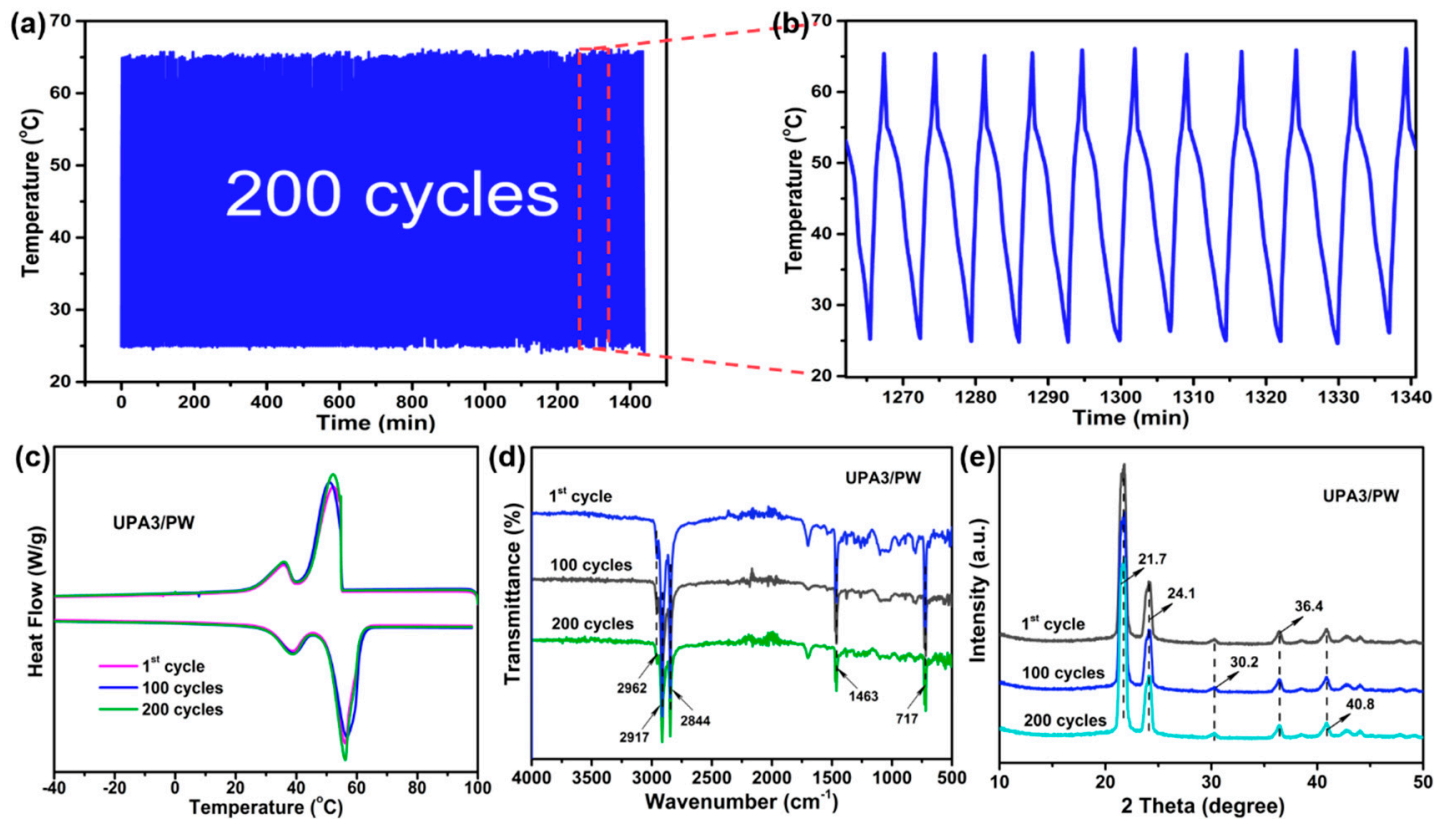

Figure 5. (a,b) Time-temperature evolution curves during 200 accelerated solar-thermal energy conversion cycling tests; (c) DSC curves, (d) FT-IR spectrum and (e) XRD patterns of the UPA3/PW before and after cycling tests.

\section{Conclusions}

In this work, we firstly fabricated a series of silver/polypyrrole composites coating PU foam (UPAx) with an impressive light absorption ability and 3D multi-porous structure. Subsequently, we designed and constructed a novel solar-thermal energy harvesting, storage and release system, in which the UPA $x$ served as building skeletons and energy conversion platform simultaneously, and PW served as latent heat storage materials. The resultant FSPCMs not only had an acceptable leak-proof performance, but also a latent heat energy storage density as high as $187.4 \mathrm{~J} / \mathrm{g}$. Meanwhile, silver/polypyrrole composites, a commendable solar absorption agent, endowed the composite FSPCMs with excellent solar-thermal energy conversion efficiency (93.7\%). In addition, 200 accelerated solar-thermal energy conversion-cycling tests proved that the prepared FSPCMs in this work provided stable and reversible solar-thermal energy conversion property, which unlocked a potential possibility in the utilization of solar energy.

Supplementary Materials: The following are available online at https:/ / www.mdpi.com/article/10 .3390 / nano11113011/s1, Figure S1: Schematic description of the formation of the FSPCMs (UPAx/PW); Figure S2: Infrared thermal image of (a) UPA3 and (b) pure PU foam under $300 \mathrm{~mW} / \mathrm{cm}^{2}$ in $1.5 \mathrm{~min}$; Figure S3: Shape stability of paraffin and the FSPCMs; Figure S4: (a) FT-IR spectra and (b) XRD patterns of PU foam and PPy; Figure S5: The thermal conductivity of PW, PU/PW, UP/PW and UPA3/PW; Table S1: Concentrations of $\mathrm{AgNO}_{3}$ and $\mathrm{Fe}\left(\mathrm{NO}_{3}\right)_{3}$ used for the oxidation of pyrrole; Table S2: DSC data of the prepared FSPCMs in this work; Table S3: Comparison of the thermal properties of the FSPCMs with other reported paraffin-based PCMs.

Author Contributions: Conceptualization, Methodology, Validation, Writing-original draft, Visualization, D.F.; Writing-original draft, preparation, Y.M.; Formal analysis, preparation, Y.J. and S.Q.; Writing-original draft, Resources, J.L.; Resources, Characterizations, Y.X.; Supervision, Project administration, Data curation, Writing-review \& editing, D.X. and Y.C. All authors have read and agreed to the published version of the manuscript.

Funding: This work was funded by the National Natural Science Foundation of China (Nos. 52002190 and 31770604).

Data Availability Statement: The data presented in this study are available on request from the corresponding author. 
Conflicts of Interest: The authors declare no conflict of interest.

\section{References}

1. Chu, S.; Cui, Y.; Liu, N. The path towards sustainable energy. Nat. Mater. 2017, 16, 16-22. [CrossRef]

2. Yuan, K.; Shi, J.; Aftab, W.; Qin, M.; Usman, A.; Zhou, F.; Lv, Y.; Gao, S.; Zou, R. Engineering the thermal conductivity of functional phase-change materials for heat energy conversion, storage, and utilization. Adv. Funct. Mater. 2020, 30, 1904228. [CrossRef]

3. Shi, T.; Zhang, X.; Qiao, J.; Wu, X.; Chen, G.; Leng, G.; Lin, F.; Min, X.; Huang, Z. Preparation and characterization of composite phase change materials based on paraffin and carbon foams derived from starch. Polymer 2021, 212, 123143. [CrossRef]

4. Tang, Z.; Gao, H.; Chen, X.; Zhang, Y.; Li, A.; Wang, G. Advanced multifunctional composite phase change materials based on photo-responsive materials. Nano Energy 2021, 80, 105454. [CrossRef]

5. Wang, Z.; Tong, Z.; Ye, Q.; Hu, H.; Nie, X.; Yan, C.; Shang, W.; Song, C.; Wu, J.; Wang, J.; et al. Dynamic tuning of optical absorbers for accelerated solar-thermal energy storage. Nat. Commun. 2017, 8, 1478. [CrossRef] [PubMed]

6. Wang, Y.; Tang, B.; Zhang, S. Single-walled carbon nanotube/phase change Material composites: Sunlight-driven, reversible, form-stable phase transitions for solar thermal energy storage. Adv. Funct. Mater. 2013, 23, 4354-4360. [CrossRef]

7. Zhang, Y.; Gurzadyan, G.; Umair, M.; Wang, W.; Lu, R.; Zhang, S.; Tang, B. Ultrafast and efficient photothermal conversion for sunlight-driven thermal-electric system. Chem. Eng. J. 2018, 344, 402-409. [CrossRef]

8. Chen, L.; Zou, R.; Xia, W.; Liu, Z.; Shang, Y.; Zhu, J.; Wang, Y.; Lin, J.; Xia, D.; Cao, A. Electro- and photodriven phase change composites based on wax-infiltrated carbon nanotube sponges. ACS Nano 2012, 6, 10884-10892. [CrossRef]

9. Chen, X.; Gao, H.; Tang, Z.; Dong, W.; Li, A.; Wang, G. Optimization strategies of composite phase change materials for thermal energy storage, transfer, conversion and utilization. Energy Environ. Sci. 2020, 13, 4498-4535. [CrossRef]

10. Kashyap, V.; Sakunkaewkasem, S.; Jafari, P.; Nazari, M.; Eslami, B.; Nazifi, S.; Irajizad, P.; Marquez, M.; Lee, T.; Ghasemi, H. Full spectrum solar thermal energy harvesting and storage by a molecular and phase-change hybrid material. Joule 2020, 4, 1-12. [CrossRef]

11. Shao, Y.; Hu, W.; Gao, M.; Xiao, Y.; Huang, T.; Zhang, N.; Yang, J.; Qi, X.; Wang, Y. Flexible MXene-coated melamine foam based phase change material composites for integrated solar-thermal energy conversion/storage, shape memory and thermal therapy functions. Compos. Part A 2021, 143, 106291. [CrossRef]

12. Maithya, O.; Zhu, X.; Li, X.; Korir, S.; Feng, X.; Sui, X.; Wang, B. High-energy storage graphene oxide modified phase change microcapsules from regenerated chitin Pickering Emulsion for photothermal conversion. Sol. Energy Mater. Sol. Cells 2021, 222, 110924. [CrossRef]

13. Mehrali, M.; Elshof, J.; Shahia, M.; Mahmoudi, A. Simultaneous solar-thermal energy harvesting and storage via shape stabilized salt hydrate phase change material. Chem. Eng. J. 2021, 405, 126624. [CrossRef]

14. Li, G.; Hong, G.; Dong, D.; Song, W.; Zhang, X. Multiresponsive graphene-aerogel-directed phase-change smart fibers. Adv. Mater. 2018, 30, 1801754. [CrossRef] [PubMed]

15. Li, S.; Wang, H.; Mao, H.; Li, J.; Shi, H. Light-to-thermal conversion and thermoregulated capability of coaxial fibers with a combined influence from comb-like polymeric phase change material and carbon nanotube. ACS Appl. Mater. Interfaces 2019, 11, 14150-14158. [CrossRef]

16. Lu, Y.; Xiao, X.; Fu, J.; Huan, C.; Qi, S.; Zhan, Y.; Zhu, Y.; Xu, G. Novel smart textile with phase change materials encapsulated core-sheath structure fabricated by coaxial electrospinning. Chem. Eng. J. 2019, 355, 532-539. [CrossRef]

17. Xue, F.; Jin, X.; Xie, X.; Qi, X.; Yang, J.; Wang, Y. Constructing reduced graphene oxide/boron nitride frameworks in melamine foam towards synthesizing phase change materials applied in thermal management of microelectronic devices. Nanoscale 2019, 11, 18691-18701. [CrossRef]

18. Jing, J.; Wu, H.; Shao, Y.; Qi, X.; Yang, J.; Wang, Y. Melamine foam-supported form-stable phase change materials with simultaneous thermal energy storage and shape memory properties for thermal management of electronic devices. ACS Appl. Mater. Interfaces 2019, 11, 19252-19259. [CrossRef]

19. Chen, X.; Gao, H.; Hai, G.; Jia, D.; Xing, L.; Chen, S.; Cheng, P.; Han, M.; Dong, W.; Wang, G. Carbon nanotube bundles assembled flexible hierarchical framework based phase change material composites for thermal energy harvesting and thermotherapy. Energy Storage Mater. 2020, 26, 129-137. [CrossRef]

20. Qiu, J.; Huo, D.; Xue, J.; Zhu, G.; Liu, H.; Xia, Y. Encapsulation of a phase-change material in nanocapsules with a well-defined hole in the wall for the controlled release of drugs. Angew. Chem. Int. Ed. 2019, 58, 10606-10611. [CrossRef]

21. Aftab, J.S.W.; Liang, Z.; Yuan, K.; Maqbool, M.; Jiang, H.; Xiong, F.; Qin, M.; Gao, S.; Zou, R. Tuning the flexibility and thermal storage capacity of solid-solid phase change materials towards wearable applications. J. Mater. Chem. A 2020, 8, 20133.

22. Cao, Y.; Fan, D.; Lin, S.; Mu, L.; Ng, F.T.; Pan, Q. Phase change materials based on comb-like polynorbornenes and octadecylaminefunctionalized graphene oxide nanosheets for thermal energy storage. Chem. Eng. J. 2020, 389, 124318. [CrossRef]

23. Wu, S.; Li, T.; Tong, Z.; Chao, J.; Zhai, T.; Xu, J.; Yan, T.; Wu, M.; Xu, Z.; Bao, H.; et al. High-performance thermally conductive phase change composites by large-size oriented graphite sheets for scalable thermal energy harvesting. Adv. Mater. 2019, 31, 1905099. [CrossRef] [PubMed]

24. Du, X.; Qiu, J.; Deng, S.; Du, Z.; Cheng, X.; Wang, H. Flame-retardant and solid-solid phase change composites based on dopamine-decorated BP nanosheets/polyurethane for efficient solar-to-thermal energy storage. Renew. Energy 2021, 164, 1-10. [CrossRef] 
25. Lu, X.; Huang, H.; Zhang, X.; Lin, P.; Huang, J.; Sheng, X.; Zhang, L.; Qu, J. Novel light-driven and electro-driven polyethylene glycol/two-dimensional MXene form-stable phase change material with enhanced thermal conductivity and electrical conductivity for thermal energy storage. Compos. B Eng. 2019, 177, 107372. [CrossRef]

26. Li, R.; Zhang, L.; Shi, L.; Wang, P. MXene $\mathrm{Ti}_{3} \mathrm{C}_{2}$ : An effective 2D light-to-heat conversion material. ACS Nano 2017, 11, 3752-3759. [CrossRef]

27. George, M.; Pandey, A.; Rahim, N.; Tyagi, V.; Shahabuddin, S.; Saidur, R. A novel polyaniline (PANI)/paraffin wax nano composite phase change material: Superior transition heat storage capacity, thermal conductivity and thermal reliability. Sol. Energy 2020, 204, 448-458. [CrossRef]

28. George, M.; Pandey, A.; Rahim, N.; Tyagi, V.; Shahabuddin, S.; Saidur, R. Long-term thermophysical behavior of paraffin wax and paraffin wax/polyaniline (PANI) composite phase change materials. J. Energy Storage 2020, 31, 101568. [CrossRef]

29. Wu, H.; Chen, R.; Shao, Y.; Qi, X.; Yang, J.; Wang, Y. Novel flexible phase change materials with mussel-inspired modification of melamine foam for simultaneous light-actuated shape memory and light-to-thermal energy storage capability. ACS Sustain. Chem. Eng. 2019, 7, 13532-13542. [CrossRef]

30. Xie, Y.; Li, W.; Huang, H.; Dong, D.; Zhang, X.; Zhang, L.; Chen, Y.; Sheng, X.; Lu, X. Bio-based radish@PDA/PEG sandwich composite with high efficiency solar thermal energy storage. ACS Sustain. Chem. Eng. 2020, 8, 8448-8457. [CrossRef]

31. Ge, J.; Wang, Y.; Wang, H.; Mao, H.; Li, J.; Shi, H. Thermal properties and shape stabilization of epoxidized methoxy polyethylene glycol composite PCMs tailored by polydopamine-functionalized graphene oxide. Sol. Energy Mater. Sol. Cells 2020, 208, 110388. [CrossRef]

32. Xu, J.; Tan, Y.; Du, X.; Du, Z.; Cheng, X.; Wang, H. Cellulose nanofibril/polypyrrole hybrid aerogel supported form-stable phase change composites with superior energy storage density and improved photothermal conversion efficiency. Cellulose 2020, 27, 9547-9558. [CrossRef]

33. Silakhori, M.; Fauzi, H.; Mahmoudian, M.; Metselaar, H.; Mahlia, T.; Khanlou, H. Preparation and thermal properties of formstable phase change materials composed of palmitic acid/polypyrrole/graphene nanoplatelets. Energy Build. 2015, 99, 189-195. [CrossRef]

34. Wei, Q.; Oribayo, O.; Feng, X.; Rempel, G.; Pan, Q. Synthesis of polyurethane foams loaded with $\mathrm{TiO}_{2}$ nanoparticles and their modification for enhanced performance in oil spill cleanup. Ind. Eng. Chem. Res. 2018, 57, 8918-8926. [CrossRef]

35. Bober, P.; Liu, J.; Mikkonen, K.; Ihalainen, P.; Pesonen, M.; Plumed-Ferrer, C.; Wright, A.; Lindfors, T.; Xu, C.; Latonen, R. Biocomposites of nanofibrillated cellulose, polypyrrole, and silver nanoparticles with electroconductive and antimicrobial properties. Biomacromolecules 2014, 15, 3655-3663. [CrossRef]

36. Zhang, Y.; Wang, J.; Qiu, J.; Jin, X.; Umair, M.; Lu, R.; Zhang, S.; Tang, B. Ag-graphene/PEG composite phase change materials for enhancing solar thermal energy conversion and storage capacity. Appl. Energy 2019, 237, 83-90. [CrossRef]

37. Li, G.; Zhang, X.; Fang, J.W.J. From anisotropic graphene aerogels to electron and photo-driven phase change composites. J. Mater. Chem. A 2016, 4, 17042. [CrossRef]

38. Kalidasan, B.; Pandey, A.K.; Shahabuddin, S.; George, M.; Sharma, K.; Samykano, M.; Tyagi, V.V.; Saidur, R. Synthesis and characterization of conducting polyaniline@cobalt-paraffin wax nanocomposite as nano-phase change material: Enhanced thermophysical properties. Renew. Energy 2021, 173, 1057-1069.

39. Zuo, X.; Li, J.; Zhao, X.; Yang, H.; Chen, D. Emerging paraffin/carbon-coated nanoscroll composite phase change material for thermal energy storage. Renew. Energy 2020, 152, 579-589. [CrossRef]

40. Huang, Y.; Cheng, Y.; Zhao, R.; Cheng, W. A high heat storage capacity form-stable composite phase change material with enhanced flame retardancy. Appl. Energy 2020, 262, 114536. [CrossRef]

41. Guo, Y.; Yang, W.; Jiang, Z.; He, F.; Zhang, K.; He, R.; Wu, J.; Fan, J. Silicone rubber/paraffin@silicon dioxide form-stable phase change materials with thermal energy storage and enhanced mechanical property. Sol. Energy Mater. Sol. Cells 2019, 196, 16-24. [CrossRef]

42. Fan, D.; Lu, Y.; Cao, Y.; Liu, J.; Lin, S.; Xiong, D.; Pan, Q. Phase change materials confined into sunlight capturer sponge towards thermal energy harvesting and storage. Sol. Energy 2021, 226, 147-153.

43. Zuo, X.; Zhao, X.; Li, J.; Hu, Y.; Yang, H.; Chen, D. Enhanced thermal conductivity of form-stable composite phase-change materials with graphite hybridizing expanded perlite/paraffin. Sol. Energy 2020, 209, 85-95. [CrossRef]

44. Zhou, Y.; Liu, X.; Sheng, D.; Lin, C.; Ji, F.; Dong, L.; Xu, S.; Wu, H.; Yang, Y. Polyurethane-based solid-solid phase change materials with in situ reduced graphene oxide for light-thermal energy conversion and storage. Chem. Eng. J. 2018, 338, 117-125. [CrossRef]

45. Umair, M.; Zhang, Y.; Tehrim, A.; Zhang, S.; Tang, B. Form-stable phase-change composites supported by a biomass derived carbon scaffold with multiple energy conversion abilities. Ind. Eng. Chem. Res. 2020, 59, 1393-1401. [CrossRef]

46. Cheng, G.; Wang, X.; He, Y. 3D graphene paraffin composites based on sponge skeleton for photo thermal conversion and energy storage. Appl. Therm. Eng. 2020, 178, 115560. [CrossRef]

47. Cao, Y.; Fan, D.; Lin, S.; Ng, F.; Pan, Q. Branched alkylated polynorbornene and 3D flower-like MoS 2 nanospheres reinforced phase change composites with high thermal energy storage capacity and photothermal conversion efficiency. Renew. Energy 2021, 179, 687-695. [CrossRef] 